\title{
Research and Experiment on Smart Remote Testing and Regulating Technology for Separate Injection
}

\author{
Zhang Peng ${ }^{1,2}$, Wu Zhenghua ${ }^{2}$, Fang Zhigang ${ }^{2}$, Li Nanxing ${ }^{2}$, Wang Yuming ${ }^{2}$, Pu Chunsheng ${ }^{1, ~ * ~}$ \\ ${ }^{1}$ School of Petroleum Engineering, China University of Petroleum (East China), Qingdao, China \\ ${ }^{2}$ Gas-lift Technology Innovation Center of TUHA, China National Petroleum Corporation (CNPC), Shanshan, Xinjiang, China
}

\section{Email address:}

zhangpeng2018@qq.com (Zhang Peng),chshpu_tx@126.com (Pu Chunsheng)

*Corresponding author

\section{To cite this article:}

Zhang Peng, Wu Zhenghua, Fang Zhigang, Li Nanxing, Wang Yuming, Pu Chunsheng. Research and Experiment on Smart Remote Testing and Regulating Technology for Separate Injection. International Journal of Oil, Gas and Coal Engineering. Vol. 8, No. 6, 2020 , pp. 167-172. doi: $10.11648 /$ j.ogce.20200806.17

Received: November 19, 2020; Accepted: December 1, 2020; Published: January 22, 2021

\begin{abstract}
The smart remote testing and regulating separate injection technology is developed in light of the problem of unable to satisfy the requirement of refined zonal water injection due to failing to adaptively control the volume of injection per the variation of formation pressure for fixed nozzle injection allocation model adopted by bridge eccentric separate injection technology as well as problems of large size of matching testing and regulating equipment \& tools, retrieving testing \& regulating approaches constrained by well deviation and injection water quality plus pressure unable to be accurately measured due to high testing and regulating frequencies etc. The remote zonal water volume control, downhole constant flow injection and real time monitoring of the wellhead flow rate, pressure and temperatures are realized by the synergy of downhole water distributor, surface control and data acquisition unit as well as the remote desktop communication unit. In the mean time, the downhole zonal flow rate and pressure data are transmitted to the control room in remote manner to realize the wellhead unmanned operation. It is indicated by the field experiment that this technology features simple process string, reliable and safe construction and testing \& regulating, sound adaptability for highly deviated and horizontal wells, which lays solid foundation for the refined low cost lean management in terms of zonal water injection wells in high water cut oilfields.
\end{abstract}

Keywords: Smart, Remote Testing and Regulating, Refined Water Injection, Deviated Well Separate Injection

\section{Introduction}

Water injection is effective approach in terms of maintaining oil zone pressure, realizing high and stable production as well as improving development performance of oilfield. The development of zonal water injection to realize effective water injection is one of the main directions of endeavor in achieving improved water flooding recovery ratio for the period of later stage of high water cut and the period of extra high water cut production [1-4].

In recent years, bridge eccentric zonal injection is one milestone for eccentric zonal injection technology with significant improvement in terms of efficiency and accuracy of testing \& regulating [5-8]. But for old oilfields, there are problems of significant disparity for different layers, quick change with water volume for zonal injection, instability with water injection volume, low dynamic conformity rate for fixed water nozzle and short period for constant water injection etc. Therefore, the zonal water injection technology develops in the direction of downhole real time monitoring and automatic control. The zonal water volume testing and regulating is realized via wireline or the running in of instruments with wireline in the later stage to regulate the downhole water distributor to achieve real time constant volume injection. Both approaches are under the pilot stage and there are problems of complicated process, operation difficulty as well as the limitation of well condition etc [9-11]. Based on the previous endeavors, a kind of smart remote testing and regulating zonal injection technology is proposed without the need to run in wireline and run in instruments in later stage in this paper to satisfy the requirement of refined zonal water injection for oilfield. The technology features simple process, suitable for vertical and horizontal well zonal water injection. The testing 
and regulating can be realized via remote desktop operation and the technical advancement of operation is high [12].

\section{Principle}

The smart remote testing and regulating zonal water injection technology is new type of zonal water injection system integrating internet and artificial intelligence (AI) technologies $[13,14]$. The new type of water distributor can control the water volume based on the formation pressure in intelligent manner to achieve the performance of even water injection. And via remote automatic testing and regulating system, the coordinated communication and control can be realized among the three parties of downhole, surface and base. The zonal testing and regulating of water injector, water well management and performance monitoring can be realized with the additional matching equipments and personnel, which lay foundation for refined reservoir water injection [15].

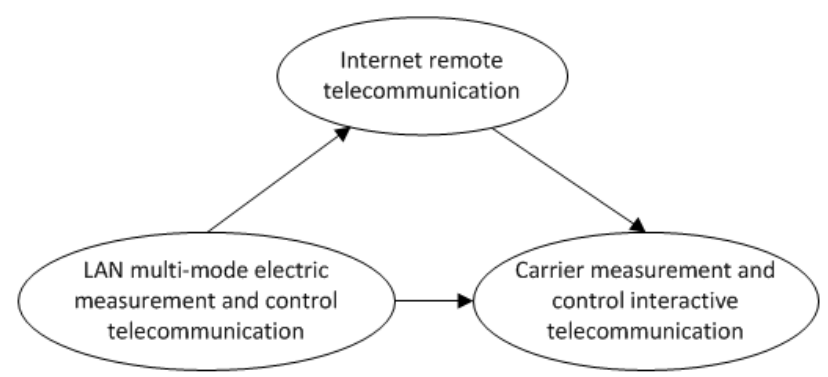

Figure 1. Framework of telecommunication system.

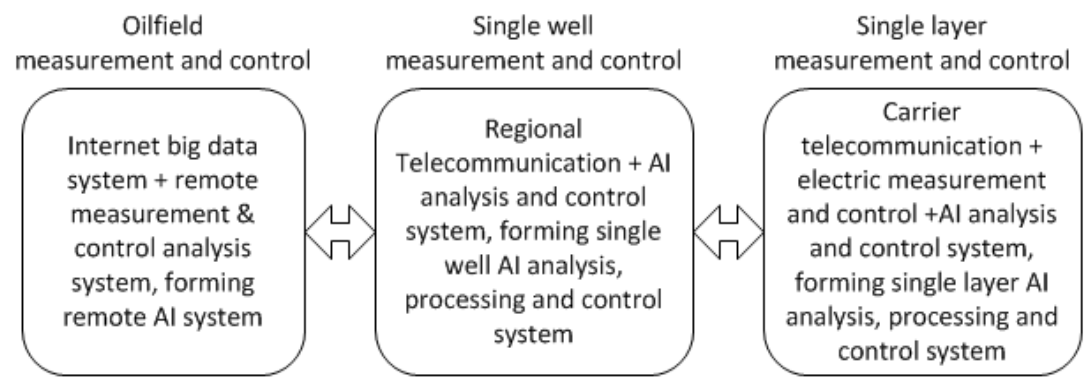

Figure 2. Framework of AI system.

\section{Configuration and Features}

System configuration: remote control unit, surface control unit, downhole control unit and downhole zonal injection string.

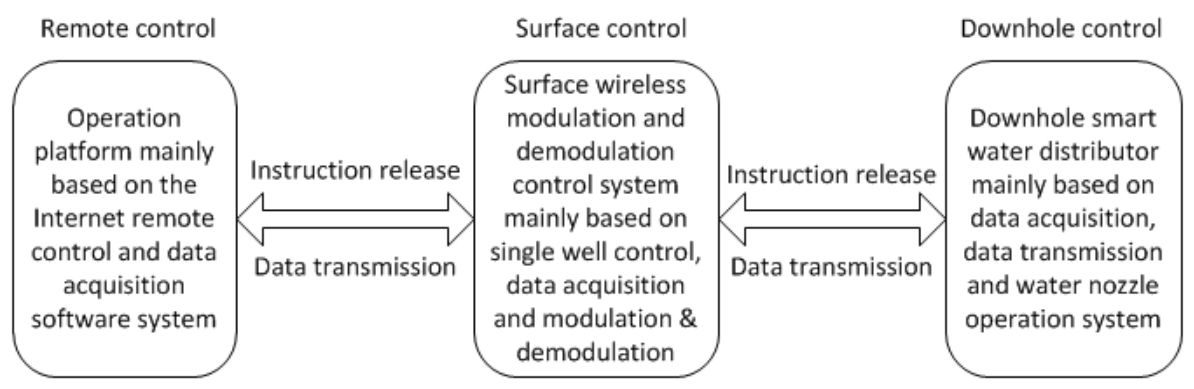

Figure 3. Overall framework of system.

Technical features:

1) Smart management system integrates data acquisition \& transmission, zonal testing and distribution as well as remote control;

2) High accuracy wireless testing and regulating overall solves the problem of limitation on testing and regulating by wellbore condition and the problems of highly deviated well and difficulty of retrieving operation;

3) AI automatic control technology realizes automatic even water injection and satisfies the interchange of distribution modes among surface constant flow, surface constant pressure and downhole constant flow injections;

4) Unmanned wellhead operation lowers operation difficulty \& cost and operation safety is enhanced;
5) Low power consumption circuit design allows $52 \%$ battery capacity consumption within 2 years and the long-term downhole power supply requirement is guaranteed.

Adjustment of downhole distribution: remote control unit and surface control unit exchange data via internet and mobile telecommunication technology; the surface control and the downhole control units exchange data via pressure pulse; the remote control unit transmits the instructions to the surface control unit, the surface control unit analyzes instruction and transmits to the downhole control unit. The downhole control unit realizes the adjustment of the opening of the water nozzle under the control of instruction to adjust the zonal water volume and in the mean time, the zonal water volume, and pressure and temperature are monitored in real time manner. 
Reading of downhole data: remote control unit sends the reading instruction. After the downhole control unit receives the reading instruction sent by surface control unit, the monitoring data will be transmitted upward to the wellhead control unit. After the wellhead control unit receives and analyzes the data, the data will be transmitted to the remote control unit.

Downhole zonal injection string is composed of anchoring \& centralizing structure, well flushable packer, new type distributor and reverse well flushing circulating valve, providing such features as sealing oil zones, zonal distribution and well flushing.

\subsection{Remote Control Unit}

The unit is composed of internet, telecommunication technology, computer \& remote control and data acquisition \& analysis software. The main functions are:

1) Release and transmit the remote control instruction;

2) Receiving and processing of remote data, including receiving and processing of surface flow rate, pressure and temperature, downhole zonal flow rate and pressure data etc.;

3) Real time analyze, process, store and display data;

4) Real time monitoring of working condition of water injectors.

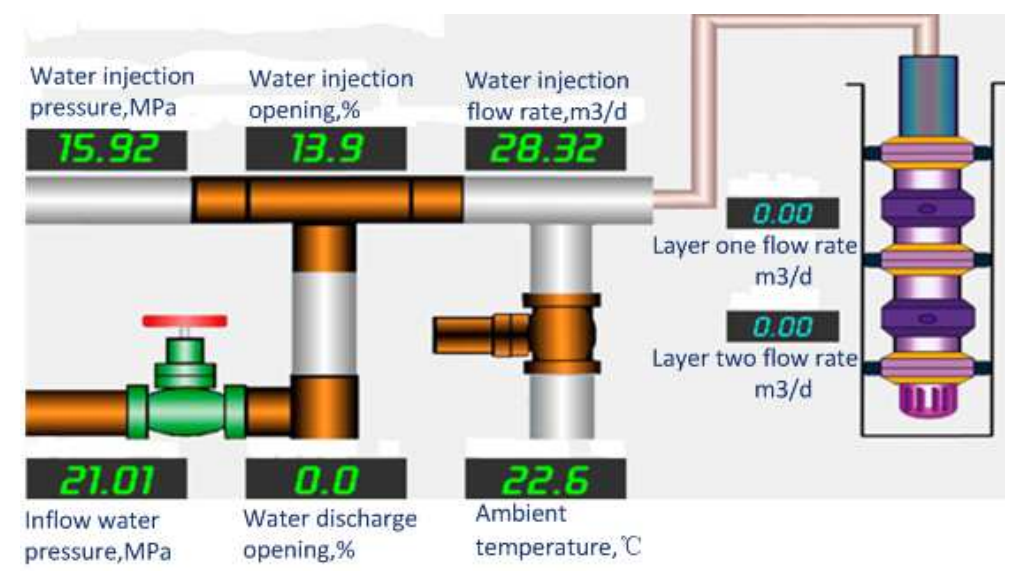

Figure 4. Schematic of remote control unit.

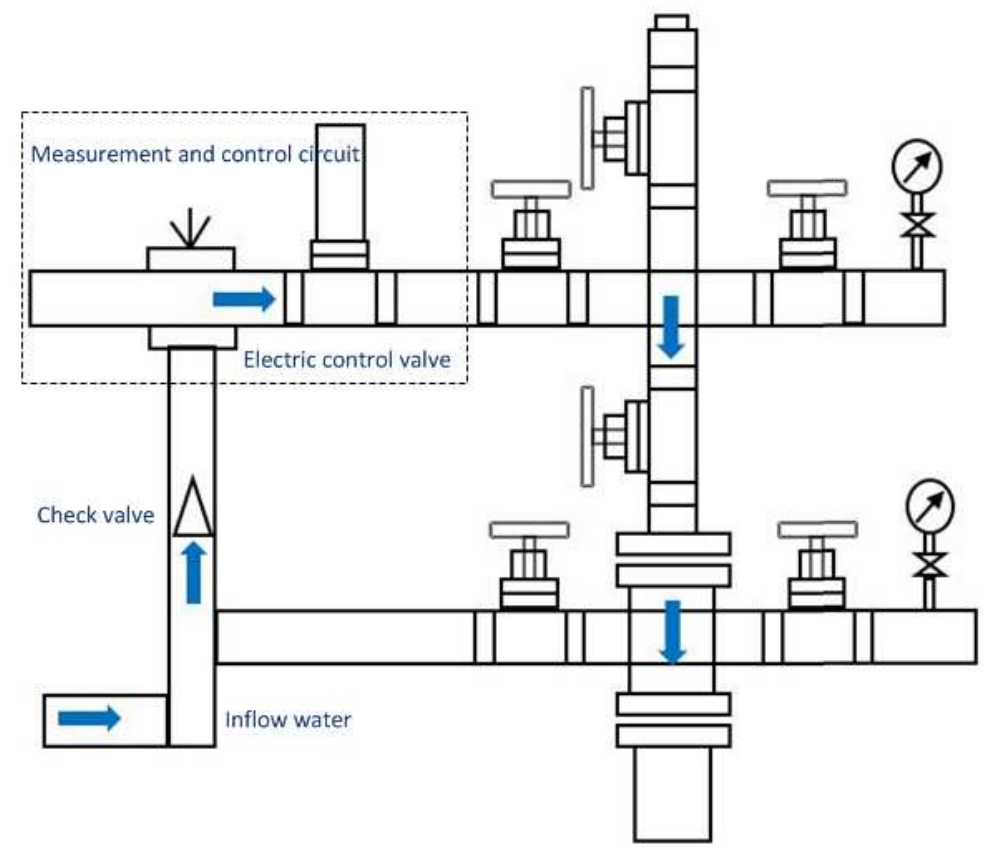

Figure 5. Schematic of surface control unit.

\subsection{Surface Control Unit}

Surface control unit is composed of smart control circuit, electric control valve, flowmeter and pressure gauge etc. and the main functions are:

1) Acquisition and transmission of wellhead flow rate and pressure data;

2) Receiving and execution of wellhead control instruction;

3) Control of opening degree of electric valve;

4) Receiving and transmission of downhole flow rate and pressure data; 
5) Transcoding and transmission of downhole water distributor control instruction.

\subsection{Downhole Control Unit}

Downhole control unit is composed of power supply system, smart control circuit system, processing software system, positioning system for work mode, eclectic pressure gauge and eclectic adjustable water nozzle etc. The main functions are:

1) Receiving and transmission of downhole zonal pressure and flow rate data;

2) Automatic smart control of downhole zonal flow rate;

3) The opening of the electric adjustable water nozzle is adjusted based on the instruction.

\subsection{String of the Downhole Zonal Injection Process}

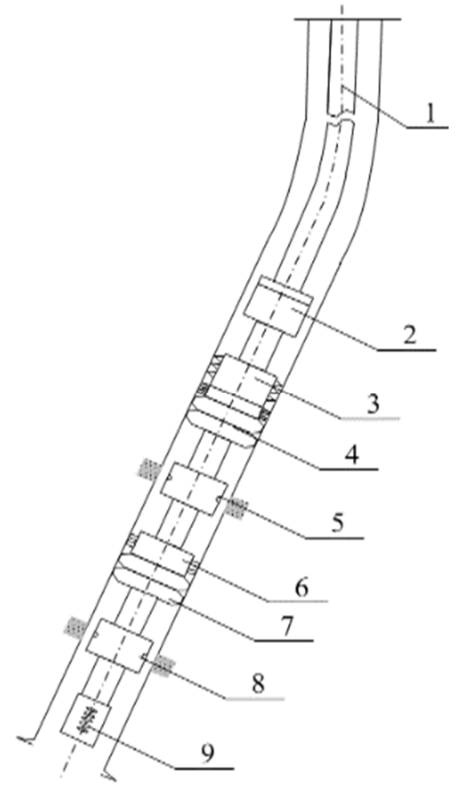

Figure 6. Schematic of downhole completion string.

1. Tubing 2. Compensator 3. Hydraulic anchor 4.7 Packer 5.8 New type water distributor 6. Centralizer 9 Reverse circulating valve

\section{Main Matching Tools}

\subsection{New Type Water Distributor}

The new type water distributor is composed of connection sleeve, power supply battery pack and downhole control unit, integrating testing, regulating and data transmission, bearing dual functions of downhole constant flow water injection and execution of artificial testing and regulating. The schematic of matching electric water nozzle is as shown in Figure 8. The structure of water nozzle is plane contact type, featuring reliable sealing, good anti-wear performance, low high pressure friction, high accuracy and full closure compliance etc.

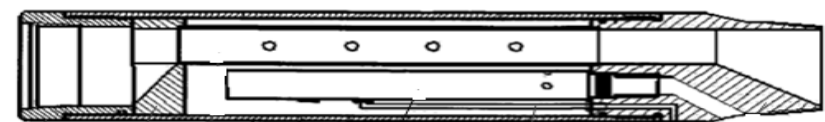

Figure 7. Schematic of new type water distributor.

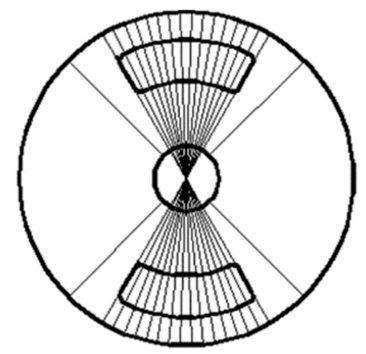

Figure 8. Schematic of electric water nozzle.

Technical parameters

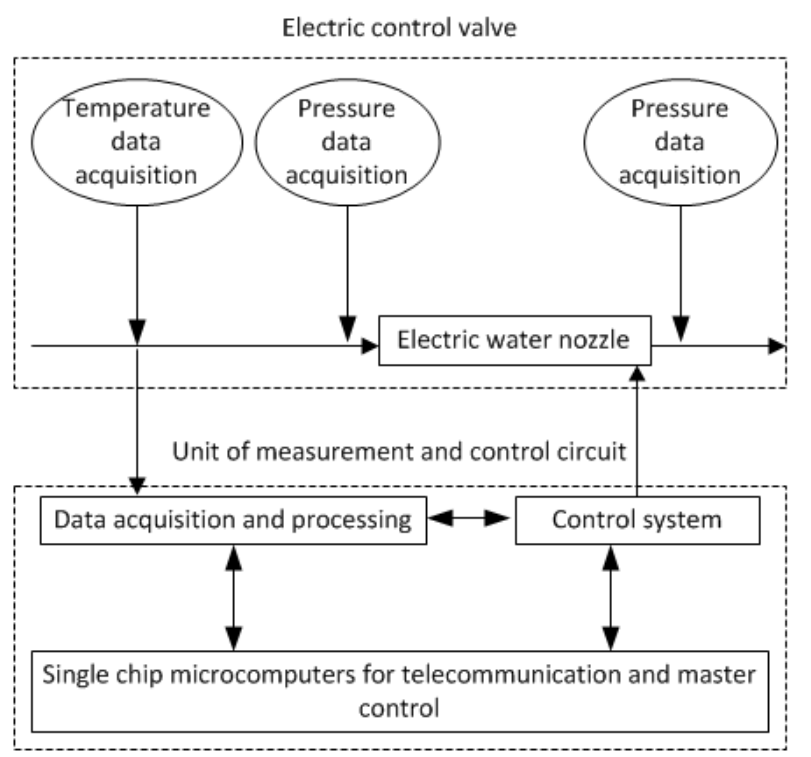

Figure 9. Schematic of surface control system.

Table 1. Parameters of new type water distributor.

\begin{tabular}{llllll}
\hline Total length $(\mathbf{m m})$ & OD $(\mathbf{m m})$ & ID $(\mathbf{m m})$ & Working pressure $(\mathbf{M P a})$ & Working temperature $\left({ }^{\circ} \mathbf{C}\right)$ & Service lif $(\mathbf{y r s})$ \\
\hline 1300 & 114 & 46 & 35 & 120 & $2-3$ \\
\hline
\end{tabular}

Table 2. Water nozzle and opening adjustment.

\begin{tabular}{llll}
\hline $\begin{array}{l}\text { Water nozzle equivalent } \\
(\mathbf{m m})\end{array}$ & Opening (major position) & Opening (minor position) & $\begin{array}{l}\text { Open } \mathbf{a r e a}_{(\mathbf{m m}}^{2} / \\
\text { major position) }\end{array}$ \\
\hline 8 & 16 & 5 & 3.35 \\
12 & 16 & 5 & 7.54 \\
26 & 16 & 5 & 30.169 \\
\hline
\end{tabular}




\subsection{Surface Control System}

The surface control system is composed of electric control valve and measurement $\&$ control circuit unit, integrating the measurement of flow rate, pressure and temperature as well as water distribution and receiving \& transmission of data, bearing the dual-function of constant flow rate water injection and constant pressure water injection as well as the functions of instruction coding, generation of pressure pulse wave and decoding etc.

\section{Completion and Water Volume Measurement and Control}

\subsection{Setting of Water Distributor Parameters}

1) The depth, number of stages and system water injection pressure of water distributor are determined based on the completion string of zonal injection design;

2) The restoration opening pressure, impressed pressure and water nozzle delay opening time of water distributor for different horizons shall be calculated;

3) Install the battery pack, and input the calculation parameters into the water distributor and the water distributor carries out self-inspection;

4) Sealing pressure of $35 \mathrm{MPa}$ shall be checked for the water distributor and when the pressure drop $\leq 0.5 \mathrm{MPa} / 30 \mathrm{~min}$, it is qualified.

\subsection{Running in the Completion String}

1) Before running in hole, the drifting and scraping shall be well carried out and then well flushing before tubing pressure testing for $28 \mathrm{MPa}$, and the pressure drop shall satisfy $\leq 0.5 \mathrm{MPa} / 30 \mathrm{~min}$.

2) The completion string shall be run in accordance with the design plan. Before running in hole, all the downhole tools shall be checked as per the inspection procedure and when conformity is confirmed, RIH can be carried out.

3) When the string is run to the design location, magnetic positioning and depth calibration shall be conducted. The location of packer shall be adjusted to be within the scope of error. The pressures of 5-10-15-20-25MPa shall be applied from tubing to set the packer and for each pressure, the pressure shall be maintained for 3-5mins; then pressure shall be slowly released.

4) The surface control unit shall be installed and the pressure \& signal testing shall be conducted and the results shall be ok.

\subsection{Testing and Distribution of Water Volume}

1) The remote control software shall be installed and the parameter setting shall be completed via the network testing and telecommunication state of wellhead;

2) Based on the monitored trial injection status, in accordance with the distribution plan, the zonal water volume adjustment shall be conducted under the rational wellhead pressure. The principle of distribution is coarse tuning before fine tuning. After the distribution of each horizon is qualified, the testing and regulating of the lower layer water volume shall be conducted when the water volume is stabilized.

3) When testing and regulating is completed, the surface control system is set as the constant pressure mode.

\section{Field Experiment}

In November, 2015, the field experiment on this technology was carried out at Tuha Oilfield. The depth of experiment well is $2594 \mathrm{~m}$, maximum well deviation is $26.91^{\circ}$, the kickover point is $2094 \mathrm{~m}$, and the water injection intervals are $2410.3 \mathrm{~m}-2421.3 \mathrm{~m}$ and $2425.1 \mathrm{~m}-2438.6 \mathrm{~m}$. The water injection medium is fresh water and the volume of distribution based on plan is $10 \mathrm{~m}^{3} / \mathrm{d}$ and $30 \mathrm{~m}^{3} / \mathrm{d}$. For parameter setting of water distributor and zonal water volume distribution, see Tables 3, 4 and 5. During the experiment, the water nozzle was opened, the transmission, receiving and execution of the instructions during testing and regulating were normal and the communication was reliable. The ultimate zonal water volumes were $10.4 \mathrm{~m}^{3} / \mathrm{d}$ and $30.8 \mathrm{~m}^{3} / \mathrm{d}$ and the design requirement of the plan was satisfied.

Table 3. Design of water distributor parameters.

\begin{tabular}{|c|c|c|c|c|c|c|}
\hline $\begin{array}{l}\text { Water distribution } \\
\text { interval } \mathbf{m}\end{array}$ & $\begin{array}{l}\text { VD of water } \\
\text { distributor } \mathbf{m}\end{array}$ & $\begin{array}{l}\text { Pressure of inflow } \\
\text { water MPa }\end{array}$ & $\begin{array}{l}\text { Pressure of hydrostatic } \\
\text { column MPa }\end{array}$ & $\begin{array}{l}\text { Restoration } \\
\text { pressure MPa }\end{array}$ & $\begin{array}{l}\text { Coding of water } \\
\text { distributor }\end{array}$ & $\begin{array}{l}\text { Opening } \\
\text { time }\end{array}$ \\
\hline $2410.3-2421.3$ & 2396 & 22 & 23.53 & 44.83 & 15180077 & close \\
\hline $2425.1-2438.6$ & 2424.39 & 22 & 23.81 & 45.11 & 15180016 & $48 \mathrm{hrs}$ \\
\hline
\end{tabular}

Table 4. Process of water volume adjustment for Pian 2.

\begin{tabular}{llllll}
\hline $\begin{array}{l}\text { Instruction } \\
\text { transmission }\end{array}$ & $\begin{array}{l}\text { Opening position } \\
\text { instruction }\end{array}$ & $\begin{array}{l}\text { Wellhead } \\
\text { pressure MPa }\end{array}$ & $\begin{array}{l}\text { Corresponding } \\
\text { volume M3/d }\end{array}$ & $\begin{array}{l}\text { water } \\
\text { Required distribution } \\
\text { volume M3/d }\end{array}$ & $\begin{array}{l}\text { Result of adjustment } \\
\text { Slightly large }\end{array}$ \\
\hline First time & 11 & 19 & 80 & 30 & Slightly small \\
Second time & 6 & 19 & 22 & 30 & Qualified after coarse adjustment \\
Third time & 8 & 19 & 32 & 30 & Qualified after fine adjustment \\
Fourth time & $8+1$ & 19 & 30.8 & 30 & \\
\hline
\end{tabular}


Table 5. Process of water volume adjustment for Pian 1.

\begin{tabular}{llllll}
\hline $\begin{array}{l}\text { Instruction } \\
\text { transmission }\end{array}$ & $\begin{array}{l}\text { Opening position } \\
\text { instruction }\end{array}$ & $\begin{array}{l}\text { Wellhead } \\
\text { pressure MPa }\end{array}$ & $\begin{array}{l}\text { Corresponding water } \\
\text { volume } \mathbf{m 3 / d}\end{array}$ & $\begin{array}{l}\text { Required distribution } \\
\text { volume } \mathbf{m} \text { 3/d }\end{array}$ & Result of adjustment \\
\hline First time & 8 & 19 & 46 & 10 & Slightly large \\
Second time & 7 & 19 & 10.4 & 10 & Qualified after coarse adjustment \\
\hline
\end{tabular}

\section{Conclusion and Understanding}

1) There is no need to run in instrument to adjust the water volume of respective layers for the smart remote testing and regulating zonal injection technology. The testing and regulating is not constrained by well deviation and enjoys advantages for zonal injection in highly deviated and horizontal wells.

2) Smart remote testing and regulating technology adopts remote control mode without the need to deploy vehicles and staff for field operation. Smart management is realized and the surface data acquisition, zonal distribution, zonal data acquisition, data transmission and remote control of water injectors can be fully accomplished. The management level of water injectors is improved and the development cost of oilfield is decreased.

3) Smart remote testing and regulating zonal injection technology is capable of conducting self-adjustment of water volume based on the variation of formation pressure. The conformity rate of dynamic distribution is high and ultimately the even water injection for the formation is achieved.

4) The wellhead control unit can be used as the constant flow and constant pressure devices in the multilayer injector and multi-well injectors in one line and the injection volume can be accurately controlled.

5) This technology shall further improve the reliability of respective units and adapt to the stability and long-term service requirement for high pressure water injection. The software shall be further improved and the capability of respective systems shall be improved to satisfy the requirements of the clients.

\section{References}

[1] Liu He, Pei Xiaohan, Luo Kai, et al. Current status and trend of separated layer water flooding in China [J]. Petroleum Exploration and Development, 2013, 40 (6): 733-737.

[2] Pei Xiaohan, Yang Zhipeng, Ban Li, et al. History and actuality of separate layer oil production technologies in Daqing Oilfield [R]. SPE 100859, 2006.

[3] Liu He, Gao Yang, Sun Fuchao, et al. Overview of key zonal water injection technologies in China [R]. IPTC 16868, 2012.

[4] Gang Zhenbao, Wei Xiufen. Review and outlook of separate layer water injection technology in Daqing Oilfield [J]. Special Oil \& Gas Reservoirs, 2006, 13 (5): 4-9.

[5] Zhu Zhengkun. The research on bridge eccentric integrated water injection technique [D]. Daqing: Daqing Petroleum Institute.
[6] Tang Jundong. Separate injection wells direct electric test and adjustment instrument for polymer flooding [J]. Inner Mongolia Petrochemical Industry, 2014, (20), 72-73.

[7] Zhang Fenghui, Hong Hai et al. Efficient testing and adjusting technology and its application in water injection wells [J]. Oil Production Engineering, 2011, 1 (2), 12-14.

[8] Xin Shuzhen. Research and application of efficient dual-flowmeter testing and adjusting technique [J]. Sino-global energy, 2014, (19), 50-54.

[9] Wang Jinzhong, Xiao Guohua et al. Research and application of multistage layered water injection in highly deviated wells [J]. China Petroleum Machinery, 2014, 42 (8), 79-83.

[10] Zhou Yupeng. Research and Application of Preset Cable Intelligent Injection Technology [J]. Oil Field Equipment, 2019, 48 (4): 69-73.

[11] ZHAO Xuliang, LIU Yongli, Research progress and prospect of intelligent separate injection technology for water injection wells [J]. PETROLEUM GEOLOGY AND ENGINEERING, 2020, 34 (4): 123-126.

[12] JU Meixin, YANG Lingzhi, WANG Zijian, LIU Yanqing. Separate injection well downhole wireless communications technology research in low-permeability oilfield [J]. PETROCHEMICAL INDUSTRY APPLICATION, 2018, 37 (1): 102-107.

[13] Chen Jingzhao. System design on numerical control water distributor of intelligent separate layer water injection [D]. Xi'an: Xi'An Technological University, 2014.

[14] Yang Wanyou, Wang Liping. A new intelligent testing and adjustment process with implanted cables for zonal water injection wells in offshore oilfields [J]. China offshore oil and gas, 2015, 27 (3), 91-95.

[15] Hu Gaixing, Wang Zijian, Bi Fuwei, etal. Transmission mechanism of fluid wave code signal in intelligent separated layer water flooding system [J]. Science Technology and Engineering, 2020, 20 (17): 6865-6872.

\section{Biography}

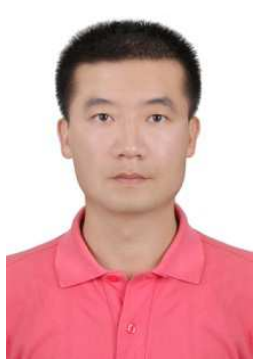

Zhang Peng (1981-), male, master, senior engineer, mainly engaged in research work on gas lift, fracturing, water injection/gas technology and wellbore safety, etc. 